\title{
Observations on the cytological diagnosis of an infectious erythema
}

\author{
CRISAN MUSETEANU AND D. VISINESCU \\ From the Children's Hospital, Cotroceni Bucharest, Rumania
}

SYNOPSIS The clinical features of an infectious erythema which affected children and young people are described. Other writers have described the same disease and have suggested a viral origin. A cytological method is described which may establish the diagnosis, and the cytological appear- $\vec{\sigma}$ ances might also be useful in differentiating between erythema and measles.

Since Beale and Campbell (1959) published their cytological method for the diagnosis of measles it has been increasingly used in routine laboratories (Henneberg and Köhler, 1961). Unfortunately we have found that the method lacks specificity, as giant cells may be seen in material obtained from cases in the early stage of a virus infection similar to measles. During the year 1957 we observed a series of children and young people up to the age of 25 presenting with a rash that did not look like that of any of the common eruptive diseases. Most of the children were of school age, they had moderate fever (between $38^{\circ}$ and $39^{\circ} \mathrm{C}$.), their general health remained good, and a rash composed of reddish, almost round papules ( 1 to $2 \mathrm{~mm}$. in diameter) spread to become irregularly shaped plaques with a diameter of about 1 to $2 \mathrm{~cm}$. The rash always appeared on the skin of the cheeks, body, and limbs, its distribution having no pathognomonic character. The conjunctivae were injected and might remain so after the rash had disappeared, leaving sensitive subjects feeling unwell for several months after the illness was clinically at an end.

Clinical examination was generally negative, except for the visible swelling of occipital or cervical lymphatic nodes. The illness lasted for two days to a week but generally it was short and mild, sometimes, however, persisting up to a fortnight. It was dangerous only when associated with a staphylococcal infection, in which case it was serious and even fatal. The illness was highly contagious and in some communities all the children were rapidly infected although only those gravely sick were considered 'ill'.

Our first observations were made on children over 3 years of age but shortly afterwards the disease Received for publication 6 December 1961.

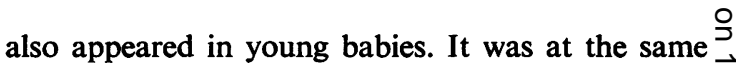
time described by other investigators, who considered $\vec{z}$ the pathogenic agent to be different types of virus. ECHO virus was isolated from faeces (Berglund, $\vec{\theta}$ Böttiger, Johnsson, and Westermark, 1958; Johnsson, Böttiger and Löfdahl, 1958; St. Geme, Prince, Scherer, and Krivit, 1959). Only Medearis and Kramer (1959) isolated an ECHO virus from blood in a single case.

German investigators (Kimmig, Rohde, and $\stackrel{๊}{\varnothing}$ Hagenow, 1959; Rohde and Lennartz, 1960) have 2 observed the same disease in extensive epidemics and $\overrightarrow{\vec{O}}$ also consider the pathogenic agent to be a large virus 3 visible microscopically and Werner (1958) has shown an analogy between the disease now called 'erythema? multiforme' and the older description of Escherich (1904) of the 'fifth disease' or 'megalerithema? infectiosum'. Starting from throat washings, Werner 3 succeeded in obtaining from tissue cultures of monkey kidney a modification which he considers specific. In these cultures he observed giant cells with split nuclei with a marked tendency to migrate towards the periphery. It is possible that the two groups of $\frac{D}{0}$ workers are not dealing with the same illness and Müller and Colli (1959) reached the conclusion that ${ }_{\sigma}^{N}$ different pathological agents were involved.

We tried to reproduce the phenomenon described by Werner on tissue cultures. We isolated and ${ }^{\omega}$ cultured the virus by the same technique as that already described (Museteanu, Museteanu, Para- - ? schivescu, and Visinescu, 1961) and inoculated the yolks of fertilized eggs with 0.1 to $0.2 \mathrm{ml}$. of a $1: 50^{-}$ dilution of blood haemolysed in distilled water and succeeded in obtaining the death of the embryo and $\overrightarrow{\mathbb{D}}$ the serial reproduction of the phenomenon. Smears? from the yolk showed granulations which stained $\propto$ bright red on treatment with May-Grünwald 


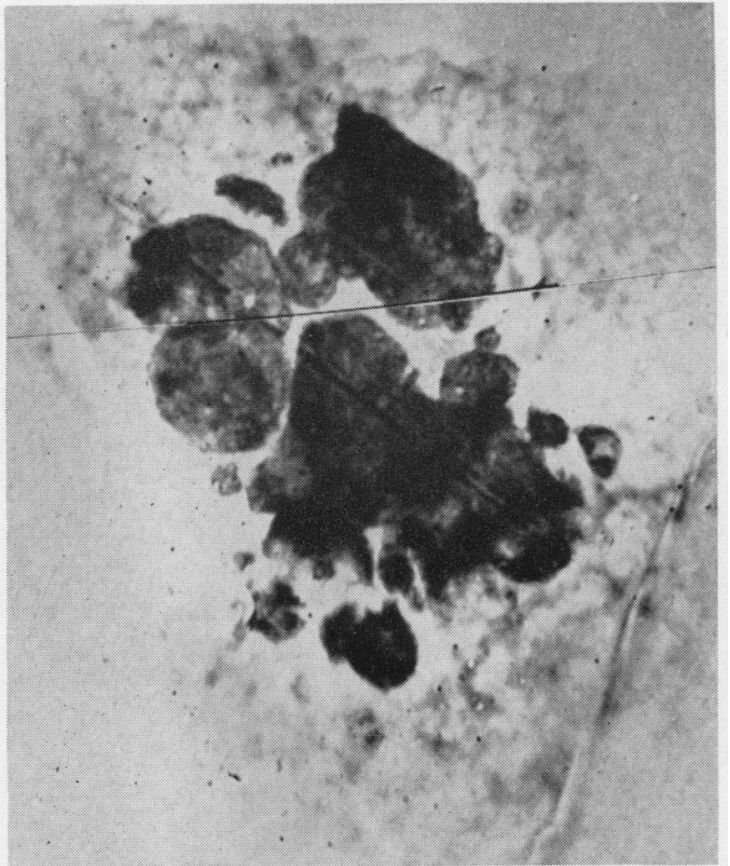

FIG. 1. Giant cells from $K B$ tissue culture, inoculated with pharyngeal washings from a case of erythema multiforme. The nucleus is split and the fragments show a tendency to migrate towards the periphery. (The line crossing the photomicrograph is due to the negative having been broken-ED.)

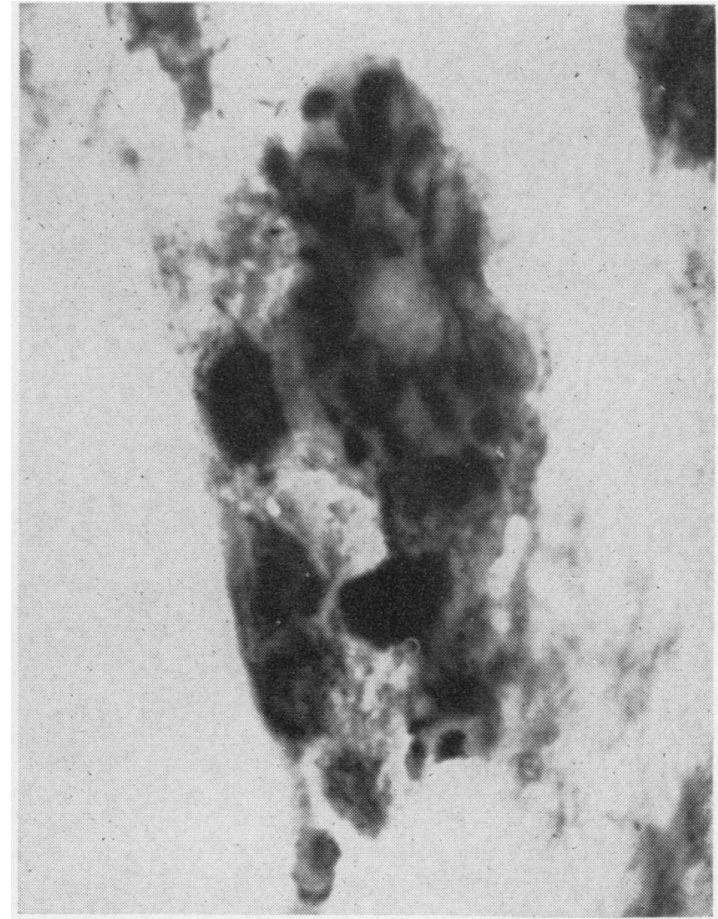

FIG. 3. Same section as Fig. 1. Fragmentation of the nucleus and migration towards the periphery may be seen. The appearance is similar to that of the tissue culture inoculated with pharyngeal washings.

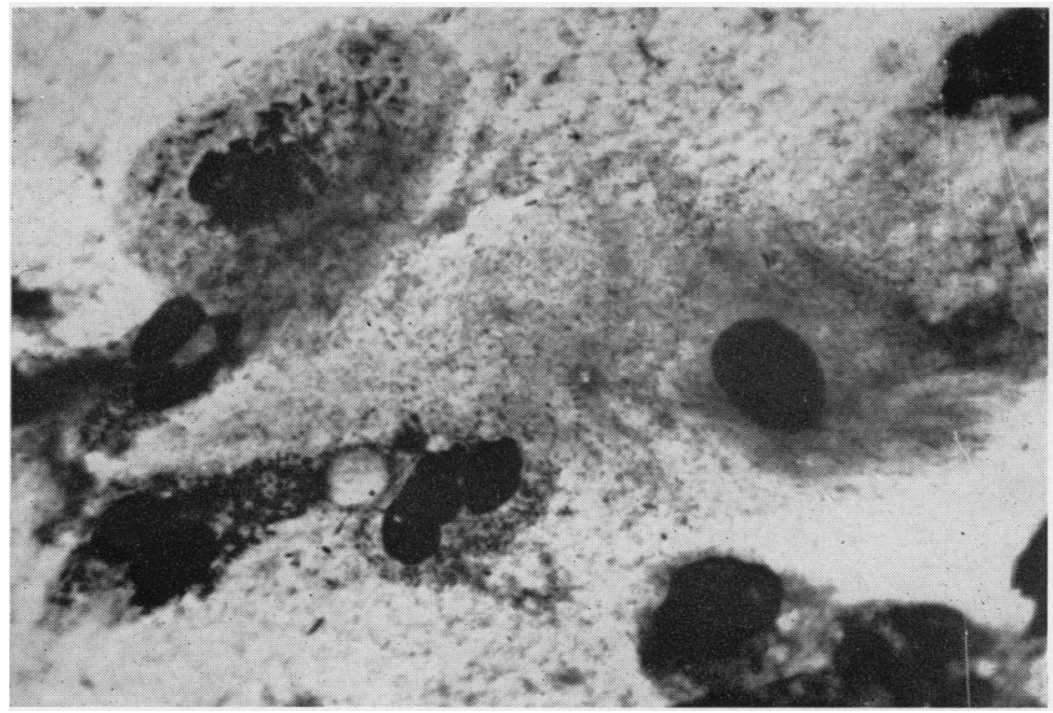

FIG. 2. May-Grünwald-Giemsa-stained pharyngeal smear from a patient with erythema multiforme. Right, a normal cell; left, the nucleus is beginning to split. 


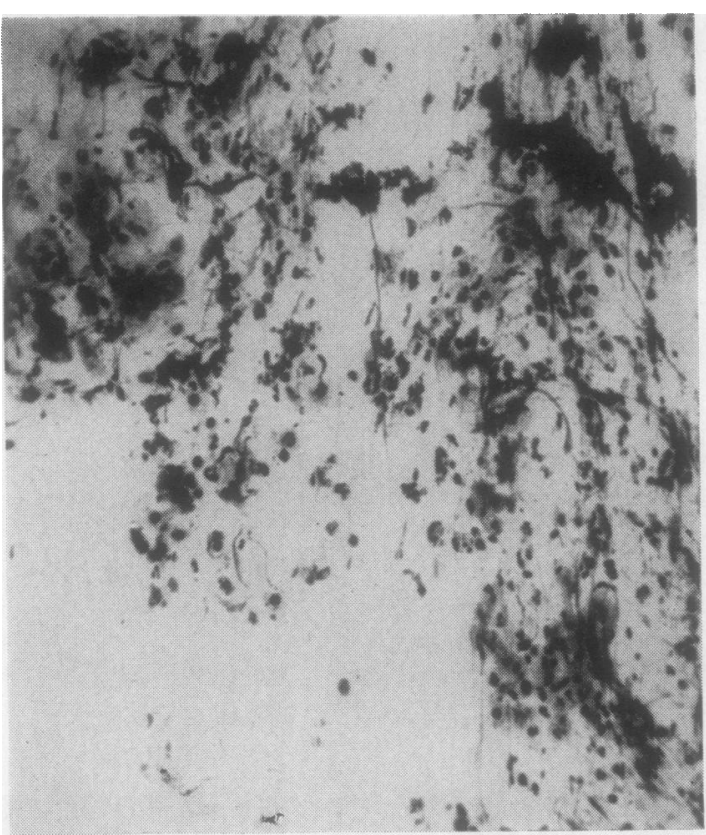

FIG. 4. May-Grünwald-Giemsa-stained pharyngeal smear of secretion from a patient with erythema multiforme, in appearance similar to that described by Beale and Campbell. An accumulation of cells and giant cells may be observed.

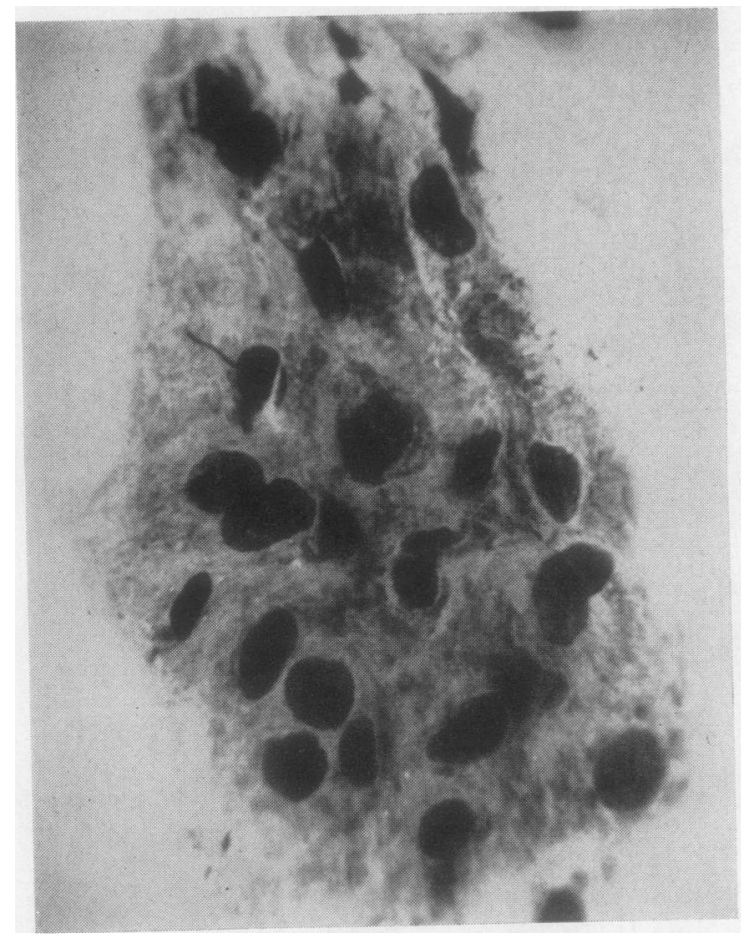

FIG. 5. High-power view of Fig. 4.
Giemsa, and we considered those to be the aetiological agent. Also, starting with the same subjects, we inoculated $\mathrm{KB}$ tissue cultures with pharyngeal washings diluted 1:100 and stained with MayGrünwald-Giemsa; pharyngeal smears were also made and stained with May-Grünwald-Giemsa. The usual cotton-wrapped swab sticks were covered with a sheet of nylon.

The results are presented in Figs. 1 to 5. Figure 1 represents one cell of a KB culture in which fragmentation of the nucleus and the tendency of the fragments to migrate towards the periphery are evident. The same phenomenon was seen in the pharyngeal smears from patients with clinical evidence of the infection. The similarity between the cells of the smear and those of the tissue culture is remarkable (Figs. 2 and 3 ). On this occasion we observed accumulations of cells as well as the formation of giant cells (Figs. 4 and 5) as described by Beale and Campbell (1959). We repeated the procedure and found that this behaviour was constant during the febrile period of the disease. As our investigations were performed in a hospital where children were brought after the rash had already appeared, we were not able to observe whether the Beale and Campbell phenomenon preceded the appearance of the rash. Thus we consider that in infectious erythema or erythema multiforme there exists a phenomenon similar to that described by Beale and Campbell in measles. If the method loses in specificity it remains, however, a simple and rapid tool for the diagnosis of this kind of eruptive fever. It may be possible that the transformation of cells into giant cells with fragmentation of the nucleus could be a test to differentiate between erythema and measles.

\section{REFERENCES}

Beale, A. J., and Campbell, W. (1959). J. clin. Path., 12, 335. Berglund, A., Böttiger, Margareta, Johnsson, T., and Westermark, E. (1958). Arch. ges. Virusforsch., 8, 294.

Escherich, T. (1904). Mschr. Kinderheilk., 3, 285.

Henneberg, G., and Köhler, H. (1961). Praktikum der Virusdiagnostik. Fischer, Stuttgart.

Johnsson, T., Böttiger, Margareta, and Löfdahl, A. (1958). Arch. ges. N Virusforsch., 8, 306.

Kimmig, J., Rohde, B., and Hagenow, J. (1959). Klin.Wschr., 37, 12. N Medearis, D. N., and Kramer, R. A. (1959). J. Pediat., 55, 367.

Müller, F., and Colli, A. (1959). Dtsch. med. Wschr., 84, 1053.

Museteanu, Crisan, Museteanu, V., Paraschivescu, N., and Visinescu, D. (1961). Stud. Cercet. Inframicrobiol., 12, 105.

Rohde, I. B., and Lennartz, H. (1960). Dtsch. med. Wschr., 85, 388.6

St. Geme, J. W., Prince, J. T., Scherer, W. F., and Krivit, W. (1959). J. Pediat., 54, 459.

Werner, G. H. (1958). Klin. Wschr., 36, 49. 